\title{
Curriculum Studies Based on Complexity Science
}

\author{
JIANG SHIHUI \& GUO SHAODONG \\ Guangxi Normal University \& He Nan University of Technology (China)
}

\begin{abstract}
Complexity science is in the forefront of contemporary scientific development; its rise and development triggered the breakthrough and innovation of methodology in scientific research. Curriculum is a complex adaptive system. Complexity curriculum research also includes nonlinearity, uncertainty, self-organization and emergent properties.
\end{abstract}

\section{Introduction}

The complexity of the curriculum and researcher's different orientations, brings about different opinions among scholars about what is curriculum research (Kiu \& Wah, 1994). Some scholars define curriculum study from different angles, such as philosophy, economics, or education; others from a research level and orientation angles; while other scholars use methodology to understand curriculum studies.

Since the 1980s, the rise of complexity science and its application in the humanities and social sciences, has not only greatly expanded the curriculum studies field, and research angles of traditional subjects, but of more importance, has also contributed to some subjects' research methodology and changed traditional ways of thinking. If we regard the school as an abode in a complex education system, so curriculum can be considered a worthy apartment in that abode. Looking at the complexities of the curriculum helps us decide the possibility and feasibility of applying complexity science theory to analyze curriculum issues.

\section{Connotations in analyzing complexity science}

Complexity science is not a turned out product; it is a new theory form developed on the basis of systems science and is the latest stage in the development of systems science. The 21st century is called the century of complexity science, "the theory and method of complexity science will provide new ideas, new methods and new ways for the development of the human race, and has very good application prospects"(Bing-hong, 2002).

Although domestic and overseas scholars have realized the significance of the study of complexity science, it is impossible to find one concept that can cover all the interests in complexity science. I believe that complexity science is a kind of "mutual discipline" 
in the new scientific research paradigm. Complexity science contains contextdependence and coexistence; we can talk of it only in a particular context not measure its complexity in universal terms. It is unrealistic and impossible to cross-level, crosscontextual, or sum up the general sense of "complexity science".

\section{An historical analysis of curriculum research on complexity}

As we all know, modern curriculum studies began in 1918. The U.S. scholar Franklin Bobbitt published a book, "The Curriculum". Then the industrial society of the United States, in a period of fanatical pursuit of social efficiency, dominated the field of curriculum studies in the same fanatical pursuit of efficiency, control, forecasting, and precision. Modern thinking with its instrumental rationality was in control of the whole process of curriculum development. The rampant raging of alienation in the modern curriculum field, turned (modern) curriculum studies into a "dying" situation (Shaodong, 2011).

Recalling the history of curriculum development in the past hundred years, we can say that the research route of complexity curriculum studies is accompanied by post-modern ideas, which is a new curriculum research idea based on a critique of the ills of modern curriculum research; it is also an important branch of post-modern ideas. The famous post-modern curriculum theory expert William E. Doll (2002) in his " 5 C's" curriculum view, explicitly points out that a curriculum course is "a complex system", he thinks that curriculum is a complex network wherein all sorts of elements mutually intertwine and function. Its forming process is evolutionary moving from simple to complex order.

The United States post-modern, curriculum scholar, Jayne Fleener, is strongly opposed to the modern socialist metaphor which takes the course as a sort of object or finished production. She stresses the relationship, the integration and dynamic side of a curriculum course, she also thinks a post-modern frame is not only the interweaving of schools, teachers, students, social discipline, and teaching materials, but also includes communication and meaning systems. As two noted Chinese scholars say, the meaning of curriculum is produced in the internal system of self-creation and self-generation (Wen-jing \& Horng-ming, 2006).

Complexity scholar Waldrop points out that a linear and mechanical course pattern is not suitable anymore, while, networks, dynamics, and a changing environment comprise today's rules. In short, today's course pattern is a complex adaptive system" (Waldrop, 1992). Through comparison with the above, and a postmodern curriculum scholar's view of a complexity research course, a modern curriculum course puts emphasis on linearity and control, with students being passive in receiving knowledge. Further, in a complexity course, research is opposed to the forecast and control of students' learning process, common in a modern course of study; instead complexivists define the course as "a flow, with an interactive and unpredictable process", advocating the learner's "vigor, self-organization, and adaptation to nature".

In the era of accepting and embracing complexity science, we want to set up a course to study road of complexity. A curriculum system is complex, nonlinear, generative and hard to predict; it is a complex adaptive system, having basic characteristics of complex systems.

\section{A complexity analysis of the characteristics of curriculum studies}

The nonlinear in curriculum research and student development

Any kind of curriculum thought is to meet the needs of society, and promote the growth and development of the students. In fact, the development of students is often 
influenced and restricted by many factors, such as environmental factors, education factors, subjective effort and so on. It's not a simple linear process, but a complex one, full of varied possibilities and non-linear processes. Each stage of students' development is filled with variety; it may be that such will not be in accordance with the design route of parents and teachers, step-by-step ahead strictly. A small thing in the student's growth process may alter the developmental track and direction of his life. Although the process of a student's growth sequence and stage may reflect a linear sequence overall, this kind of linear is relative, only an approximate fuzzy processing of the nonlinear.

\section{The nonlinear in curriculum implementation}

Curriculum implementation is to advance a design course plan into a specific action process. Curriculum scholar J.B. Snyder says that, according to the curriculum implementation process of a specific course of action faithful to lesson plans, will influence curriculum implementation factors into a reform of the whole situation: campus, school levels, and the external environment. He sees four major categories with 17 kinds of specific factors. This shows that curriculum implementation is by no means a liner, simple process -- from A (the ideal curriculum plan) to B (the reality of the operation of the curriculum). Factors influencing curriculum implementation are diverse and complex.

In the process of curriculum implementation, advance design and planning can only be regarded as tools of curriculum implementation. They are like a travel guide, rather than the blueprint of construction; they provide us with only the possibility of curriculum development. Initial curriculum plans are a starting point for teachers in curriculum implementation, not the end of course implementation.

In curriculum of implementation, we should adjust according to the specific situation. Curriculum implementation as a process is nonlinear, the open system limited by only by the specific situation; it is not a linear, closed system.

\section{The uncertainty of the curriculum research and knowledge}

Curriculum story: "Send the Prime Minister down the kilometer street" - New interpretation. (Ze-yuan, 2006)

Do you know the text "Send the Prime Minister [his hearse] down the kilometer street" [a main ceremonial boulevard in Beijing]? I have firm belief of my own teaching ability, feel the class is good, and I also copy segments from the Internet. Probably for no more than ten or twenty minutes, our generation has such an education, knowing much deeper than today's children. My eyes became red when I saw it. When they saw the children crying toward the direction of the hearse's movement, the children were smiling. Then I severely criticized them, said this was impolite to our beloved premier Zhou! I forced them to see it again. This time, they really couldn't laugh. I knew children's affection is not to be forced. They didn't laugh this time. Last Friday, by themselves they played a skit entitled "Send the Prime Minister in the kilometer street", I was very happy, because the children were performing the textbooks, but in my heart I was wondering how to play this textbook drama? First walked in two girls, standing there, and then four boys carried in a body. The two girls said, "The body of the prime minister is coming," and began to cry, and other children also began to cry: "Prime Minister, ah, you die very miserably! "Two boys cried, "prime minister, ah, you really go so early, you owe me twenty thousand bucks, how can you pay me?"

The students are fresh with life of the individual in the change of development; curriculum, in a sense, is the carrier of the material for a student in the course of growing up. This story tells us static text materials can produce different emotional experiences under different backgrounds for students. This shows that to rely on sure 
course knowledge (material) to regulate and constrain students' growth process is unrealistic; we may need to pay the costs of risk-taking.

The real world is always developing and changing, knowledge of the world may not blindly be at rest, a closed, conservative situation. We are living in a world full of uncertainty. Although scientists have often proclaimed "the end of uncertainty", in real life uncertainty continues. Some, like the pious "religious believers", are still sentimentally attached to the easy control of certainty prospects; "Certainty magic", it might be called. Under the communist-controlled knowledge view, knowledge is waiting for people to find it, it is motionless, closed, and exists in natural law in a closed system.

The philosopher Zhao Ting-yang points out that in the face of uncertainty knowledge, "on the one hand, no longer look for knowledge as eternal truths, pay attention to grasp the uncertainty of knowledge; on the other hand, no longer take knowledge completely as an abstract symbol, especially pay attention to grasp the cultural, and reward knowledge beyond a single 'tools rational' concept, associate knowledge with the human situation, destiny and happiness" (Ting-yang, 2001).

Curriculum knowledge (content) is the core factor of the curriculum system, according to the needs of economic and social development as a realistic requirement; the educated body and mind of the law of development; the constantly updated science and culture of knowledge. Curriculum knowledge (content) needs to be constantly updated and adjusted, it is not static. The dynamic curricular knowledge view (Fleener, 2002) need us to use the development and changed point of view to see the essence and characteristics of curriculum knowledge.

\section{The uncertainty of curriculum implementation}

Curriculum story: "The frog jumps back in the well" (Yong-kang, 2003)

"The Frog in the Shallow Well" story is quickly learned; the Chinese teacher let students open the wings of imagination, take "the frog jumps out of the well" as a topic to say a few words. The students, speaking one by one, say the content is "the outside world is wonderful" or "the frog really realized his little experience ". At this time, a student says, "the frog jumps out from the well, takes a look, feels good in the well, jumps back in the well." Voices fade, students then belly laugh. The teacher is "humorous", he freely says, "I see you are a frog, and sit in the shallow well."

In this case, maybe some teachers will say "if you don't understand, just keep silence. No one would say you are dumb!" Could it be said that the student's point of view is no sense? The student still insists on his ideas; in the class writing, he writes: "the frog jumps out of the well, comes to a river and wants to drink water, suddenly, he hears a warning from the old frog "don't drink, water toxic!" And then, he hears the shrieks of the old frog that was stabbed to death by a fork [...]" See here, we finally understand, why the student will say the frog still "feels good in the well". He associated the environmental pollution with life outside the well, what a wonderful view! Such a thoughtful and creative child! Unfortunately, the teacher did not let him fully express his point of view in the classroom. Just think, if the teacher was at that time in the class to ask: "Why did the frog jump back into a well?" What will happen in the class? I think, the whole class would no longer laugh at him, and would cheer for his amazing imagination and creativity.

Superficially, the teacher in the curriculum story respected the students, which allowed the students to imagine freely how to experience their own understanding of the curriculum story. However, he limited and controlled the rich imagination of the students to two views, which were "the outside world is very exciting" and "the frog truly feels his new experiences". So when the student in the case said the frog jumped 
out of the well and looked outside, only to find that the well was good and so it jumped back into the well, the teacher dealt with such wonderful classroom creativity, which surpassed his expectation, with irony, sarcasm and even suppression. Thus, the teacher's curriculum implementation stayed only on the default level of the curriculum implementation; he was afraid of the appearance of "uncertainty" during the curriculum implementation process.

Foreign scholar Keith Morrison has said: "It is difficult for curriculum areas to resist the temptation of 'certainty'". If we know what we want to do, what is the purpose, why we should do this, how we should do it, and the extent to which we achieve the desired goal, then we are able to provide a curriculum model for government and policy makers which is attractive and can be used for explanations" (Morrison, 2003). In addition, influenced by mechanicals, simplistic, linear, modern scientific thinking, curriculum implementation is simply seen as linear and static, the faithful implementation of the curriculum planning process. Uncertainty and dynamic creative generation have been neglected in the implementation of the curriculum by teachers.

\section{Self-organization of curriculum study and curriculum implementation}

Curriculum story: Spring Wind, "waking up" the grass (Ze-lin, 2003)

When the teacher was teaching "the first flower apricot", enjoying "spring green willow, green grass, blowing to ripple the water, blowing drum apricot buds," such beautiful sentences, a student asked, is "green" the wrong word here? Faced with the sudden "rise in revolt", the teacher quickly grasped the "creation" occurring in the classroom as an opportunity for students to appreciate the changes and the accumulation of quotes in the story. He immediately created an innovative space for divergent thinking and asked the students with a smile, "where is its fault?" The student presented his reasons: "Green" is repeated. I feel that "waking up" is good. Spring girl came; sleepy grass woke up and stuck up a small head." The teacher continued to encourage and inspire students to their innovation: "You dare to challenge the textbook. I admire you. Do you have any other comments?" The teacher's words inspired all of the students' debates on this material's fault. Finally, there were three insights: (1) with the "waking up", which could avoid "blow green willow" in the green's repetition, but also the grass was alive. "Green" was too common and it is obviously the imitation of "spring green river south"; (2) "Green" was good, because the text was not written in the early spring, but the opening season of the apricot. The grass had woken up, and now had been green; (3) "Good" was good, but the sentence order should be changed to: "Spring breezes rippled the water, blowing wakes up grass, blows green willow, the apricot buds blow the drum." The reason: spring comes, the river thaws, grass sprouts, willows Tulu, apricot blossoms; "wrinkle - wake up - Green - drums" not only write the features of spring landscape, they also show the passage and change of time.

From the story we could find that when the student who asked "in 'blowing green grass' is 'green' a wrong word", an accident occurred in the classroom. If the teacher disregarded the student's question or regarded that student as disrupting the order of the classroom, the next exciting story would not have happened. But the teacher did not teach that way. On the contrary, he seized the excellent opportunity in time. Furthermore, he guided the students on the materials "wrong" for a step- by-step question and exploration, using his own teaching wit and wisdom, of course, and eventually it formed three insights, which reached new, higher, more creative forms of self-organization of curriculum implementation.

Thus, in the process of curriculum implementation, knowledge was not imposed from the outside to students, but a process that was selective and active self-construction based on their existing cognitive structures and knowledge systems and a process 
through self-organization to help move their own cognitive system from imbalance to balance, from no (or imposed) organization to self-organization.

This curriculum system was not a closed system, but an opening system that constantly exchanged material, energy, information with the outside. It was the same as a subsystem of curriculum implementation. The curriculum implementation process is a continuous coordination process of teachers, students, teaching materials and environmental factors and re-establishes in the implementation process new norms, leading to a new ordered structure of a self-organizational process.

\section{The cyclical nature of mutations in the curriculum paradigm}

Catastrophe theory is very important to self-organization theory. What it studies is the conversion between balanced points. Catastrophe theory is beneficial to deepen our understanding diversities of a system's changing of order and disorder. During curriculum development in our Chinese history, there have been many different curriculum paradigms. In a certain period of time, the generation and conversion of curriculum paradigms of programs embody the paradigm of mutation. Curriculum paradigm mutation refers to two wholly different courses of conversion and elimination in curriculum. After the old curriculum paradigm passed, a qualitative, new curriculum philosophy, curriculum development concept arose to replace the old paradigm.

In accordance with the historical development of the school curriculum, Professor Huang Fu-quan analyzed various curriculum paradigms that existed in the school system in the history of human development. He believes that from $4500 \mathrm{BC}$ to the 1950s, in the history of school curricula there existed four different curriculum paradigms: the "original" curriculum paradigm, "Art" curriculum paradigm, "discipline" curriculum paradigm, and the "experience" curriculum paradigm (Fu-quan, 1998).

\section{The emergence of curriculum study}

Complexity science in terms of the system as a whole or in part with the sum of the parts does not possess the attributes, characteristics, behavior, and function as the emergence of features. Although emergence is a phenomenon and the overall feature, not all the characteristics of the phenomenon are emergence. Simply adding up the characteristics of the various parts of the system does not produce emergence, for emergence depends on a dynamic relationship, including a sense of resistence, among the specific characteristics of the interaction between the parts. Only then can the form be called emergence (Shi-yong, 2006).

\section{The emergence of the curriculum system}

What the emergence of the system refers to is the system as a whole, not the particular attributes, characteristics, functions, behaviors and so on of the components. The curriculum system is not closed, but is an open, interconnected organic whole; it is constantly engaged with the outside material, energy, information exchange, and feedback

In the overall operation of the curriculum system as a whole the following three conditions are possible:

1. "Incompatible conditions": Various subsystems, "each singing a different tune," are not only not able to cooperate and support each other, but through a variety of ways and means destroy the other functions in the play of interactions, leading to the destruction of the sub-structure and function reduction, or even lead to the collapse of the system itself;

2. "Isolated operation conditions": Various subsystems run as usual, but between systems and the exchange mechanism there lacks communication, or we can say systems 
appear as a barrier to communication and coordination. All of the parts are just playing the sub-function of the system itself closely and mechanically, and even the overall structure of the "cumulative" characteristic has not been achieved. In this case, the curriculum operation of the system cannot achieve self-organization, emergence of systems will be impossible to produce;

3. "Emerging condition": Various subsystems have mutual cooperation, mutual support and they co-operate towards common goals. Curriculum systems achieve the optimal combination of structure during this operation. The emergence phenomenon of the curriculum system has the greatest degree of release and the curriculum features have the greatest play of interactions.

\section{Emergence during a running coupling of the course structure}

The curriculum structure is comprised of curriculum elements, the components of the combination of internal relations and mutual forms of organization. The school curriculum structure is not a simple sum of the elements of a mechanical system composed of rigid components, but is an organic whole. The overall course structure is optimized to run on the basis of the coupling network. The function of the school curriculum to achieve the realization of the operation depends on the course structure coupled to the emergence of resistance.

To measure whether the course structure has reached the emergence of the coupling operation, there are at least three measures (Zhe-xun \& Hui-sheng, 2003): (1) whether the curriculum courses within the system's boundaries and the set of subjects and activities are reasonable; that is whether they provide the basis for the mechanism of sequence changes, and possess flexibility in course structure; (2) whether the curriculum system is fully coordinated as to form an organic whole; (3) whether during the process of the optimization of the course structure, there exists continuous feedback and adjustment.

\section{Conclusion}

To look at and examine the school curriculum from a complex scientific theory helps us understand, interpret, and handle complex curriculum issues, and helps us to master the complexity of the curriculum system during the practice of specific curriculum reform. At the same time, it also has some practical significance and inspiration value for our understanding and awareness of the current systemic reform of basic education: its curriculum, complexity, difficulties. Now, the complexity of curriculum studies is in the ascent, although its research mission still has a long way to go. We're just on the road.

\section{References}

Bing-hong, W. (2002). The second complexity science and economic physics international academic conference proceedings. Guangxi, China: Guangxi Normal University

Complexity and Education (2011). Glossary Inquiry: Curriculum. Retrieved from: http: / / www.complexityandeducation.ualberta.ca/glossary/g_curriculum.htm.

Doll, W. E. (2002). Ghosts and the curriculum. In W. E. Doll \& N. Gough (Eds.), Curriculum visions (pp. 23-70.). New York: Peter Lang.

Fleener, M. J. (2002). Curriculum Dynamics: Recreating Heart. New York: Lang.

Huang F. (1998). On the course of periodic paradigm mutation rate. Curriculum Journal of Teaching Material and Method, 5, 7-12.

Kiu, L. C. \& Wah, W. H. (1994). Curriculum: Paradigm, Perspectives and Design. Beijing, China: The Chinese University Press.

Morrison, K. (2003). Complexity Theory and Curriculum Reforms in Hong Kong. Pedagogy, Culture E Society, 11(2).

Shaodong, G. (2011). The Alienation of Modern Curriculum Studies. Journal of Educational Measurement and Evaluation 8, 25-28. 
Shi-yong, L. (2006). Nonlinear science and complexity science. Harbin: Industrial University Press.

Ting-yang, Z. (2001). Knowledge, destiny and happiness. Journal of Philosophical Research, 8, 36-41.

Waldrop, M. (1992). Complexity: the emerging science at the edge of order and chaos. Harmondworth, England: Penguin.

Wen-jing, S. \& Horng-ming, J. (2006). On Jayne Fleener's Postmodern Curriculum Theory and Its Implication. Journal of Curriculum Studies, 2, 69-96.

Yong-kang, T. (2003). Learn to listen to. Wen Wei Po.

Ze-lin, F. (2003). Make the classroom a "mistake" as a curriculum resource. Journal of Peoples Education $17,35-36$.

Ze-yuan, Y. (2006). Curriculum change and school curriculum leaders. Chong Qing University Press.

Zhe-xun, L. \& Hui-shen, T. (2003). New approach to curriculum theory. Beijing, China: Education Science Press.

\section{About the Authors}

Shi-Hui Jiang is Professor in Curriculum \& Instruction at Guangxi Normal University in China. He received his Doctoral degree at East China Normal University in 1998. His main research interests focus on curriculum \& instruction theory, curriculum reform of basic education in China, educational equality. He has published many papers in Chinese academic journals and presented at numerous national and international conferences. His two books, An instruction to curriculum change (Xueyuan Publishing House, Beijing, 2003), the issues of educational research in the contemporary China, (Guangxi Normal university Publishing House, Guilin, 2003) have attained higher review in educational circles.

Guo Shao-Dong is Assistant Professor in the school of management at Henan University of Technology in China. He received his Master Degree of curriculum \& instruction at Guangxi Normal University in 2009. His main research interests focus on complexity theory in curriculum and instruction, career development of college students. His main research papers include "The research on Methodology of Complexity Science" (The Journal of Guangxi Normal University (Philosophy and Social Sciences Edition, 2009)," An Overview of Researches on Curriculum Localization since Reform and Opening in China" (Jiang Su Educational Research, 2008).

(C) Copyright 2012. The authors, Jiang Shi-Hui \& Guo Shao-Dong, assign to the University of Alberta and other educational and nonprofit institutions a non-exclusive license to use this document for personal use and in courses of instruction provided that the article is used in full and this copyright statement is reproduced. The authors also grant a non-exclusive license to the University of Alberta to publish this document in full on the World Wide Web, and for the document to be published on mirrors on the World Wide Web. Any other usage is prohibited without the express permission of the authors. 